\title{
EL NEGOCIO AUTOMOTOR EN PATIOS DE AUTOS USADOS
}

\section{SONDEO DE OPINIÓN APLICADO}

\author{
ANA MARIA SÁNCHEZ1 FERNANDO MAYORGA² \\ TATIANA VAYAS ${ }^{3}$ CAROLINA FREIRE 4
}

\section{EN EL GANTÓN AMBATO}

\section{Resumen}

Siendo la actividad comercial una de las más representativas dentro de la economía de la provincia de Tungurahua y frente a las medidas restrictivas impuestas a la importación de vehículos en el Ecuador, el Observatorio Económico y Social de Tungurahua OBEST, realiza un estudio a este sector para determinar el comportamiento del comercio de vehículos usados en Ambato y sus perspectivas de crecimiento. Se recoge información primaria mediante cuestionario aplicado a representantes de patios de vehículos usados del cantón Ambato y obtiene información que evidencia la situación real de este sector comercial en lo que va del año 2016.

\section{Palabras clave:}

Medidas restrictivas de importación, comportamiento, vehículos usados, situación real

\section{Abstract}

The commercial sector being one of the most representative sectors within Tungurahua's economy and given the restrictive aspects imposed on the importation of cars in Ecuador, the Economic and Social Observatory of Tungurahua - OBEST, has performed an investigation of this sector in order to determine the used car trade behavior in Ambato, including its growth expectations. The OBEST has collected the primary information through questionnaires which were applied to the representatives of the used car business and obtained information that showed the commercial sector's real situation during the time that has transpired of 2016.

\section{Keywords:}

Import restrictive aspects, behavior, used cars, real situation

\section{Introducción}

En publicaciones anteriores el Observatorio Económico y Social de Tungurahua - OBEST, realizó análisis sobre el comportamiento de ventas en el negocio automotor en Ambato y Tungurahua. La información de vehículos usados se recolectó mediante el Primer Sondeo de Opinión a comerciantes de este tipo de vehículos en la feria que se desarrolla en la parroquia Picaihua del cantón Ambato, mientras que los datos de vehículos nuevos se obtuvieron de los anuarios de la Asociación de Empresas Automotrices del Ecuador - AEADE

El escenario para ambos tipos de vehículos fue similar, tendencia a la baja en ventas en el año 2015 y lo que va de 2016. Con este antecedente, se decide realizar un segundo sondeo de opinión a comerciantes de autos usados, pero en esta ocasión, en patios de carros ubicados en la ciudad de Ambato. La investigación recoge información de 37 locales comerciales que fueron visitados en el mes de agosto de 2016 y que estuvieron dispuestos a colaborar.

\section{Contenido}

Siendo Ambato uno de los cantones más comerciales del país, se encuentran patios de autos usados con una trayectoria que van desde 1 hasta 30 años. Dentro de esta investigación no se encontró negocios de menos de un año en esta rama, en tanto que alrededor del $47 \%$ de encuestados llevan más de 8 años en el mercado.
Los vehículos que representan mayor porcentaje dentro de las ventas en patios de autos usados (59.5\%), son los livianos, apenas el $5.4 \%$ comercializa vehículos pesados, mientras que el restante $35.1 \%$ se dedica a ambos tipos de vehículos.

Los patios de autos usados están a cargo en su mayoría por empleados, gerentes, administradores y vendedores, de los cuales, más del $80 \%$ cuenta con educación superior.

Figura 1. Tipo de vehículos que se comercializan en patios de autos usados Ambato 2016

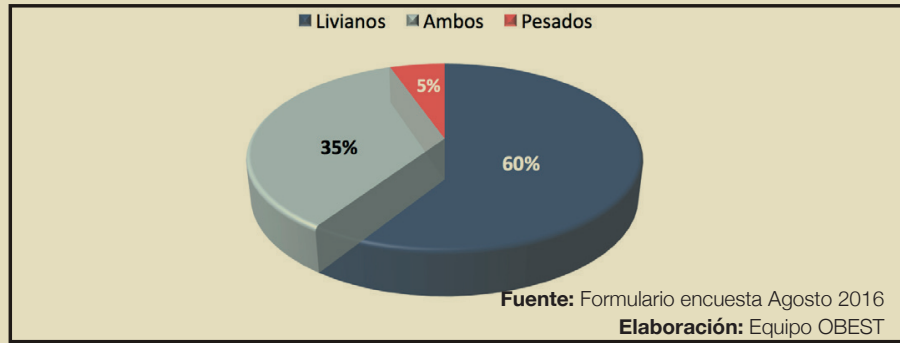

De acuerdo a la AEADE el segmento de automóviles nuevos tiene un precio promedio de $\$ 18.300$ dólares por unidad. Los clientes de patios de carros usados buscan un precio promedio de compra de $\$ 12.200$ dólares de acuerdo a sus necesidades en vehículos livianos, mientras que en la línea pesados el precio promedio es $\$ 31.000$ dólares. Ante la variedad de precios el cliente se enfrenta a decisiones en base a lo que puede ofrecer el mercado.

El número promedio de empleados que trabajan en patios de vehículos usados es 5 personas, sin embargo, existen locales que funcionan con un solo empleado, hasta locales que trabajan con 20 personas. De 37 encuestas realizadas en este sector comercial, se evidenció que emplean a 188 personas contribuyendo al desarrollo económico del cantón.

De acuerdo al Primer Sondeo de Opinión a Comerciantes de Autos Usados en la feria del cantón Ambato el $76 \%$ de informantes afirma que sus ventas han disminuido en relación al año pasado. La misma afirmación hace el 95\% de informantes de patios de autos usados, ninguno de ellos considera que sus ventas hayan aumentado y apenas el $5 \%$ afirma que la cifra de unidades comercializadas es igual a la registrada en el año 2015. Se observa contracción de la demanda de vehículos tanto nuevos como usados en el año 2016. En la Figura 2 se puede observar que de acuerdo a ambas investigaciones, la situación en lo que va del 2016, ha desmejorado en relación al 2015. El mismo escenario se reporta por parte de concesionarios de autos nuevos en la ciudad de Ambato.

Economista - Especialista de Investigación y Desarrollo Observatorio Económico y Social - OBEST - UTA

Ingeniero en Ciencias Económicas y Financieras. Analista de Investigación y Desarrollo del Observatorio Económico y Social de Tungurahua - OBEST de la Universidad Técnica de Ambato - UTA

${ }^{3}$ Economista - Analista de Investigación y Desarrollo del Observatorio Económico y Social de Tungurahua - UTA

4Ingeniera Comercial - Analista de Investigación y Desarrollo del Observatorio Económico y Social de Tungurahua - UTA 
Figura 2. Comportamiento de ventas en feria de autos usados y patios de autos usados

Ambato 2015 - 2016

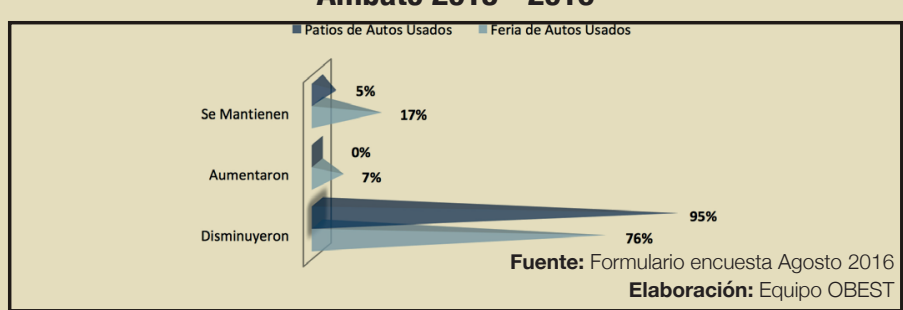

Haciendo referencia a precios, a pesar de la reducción en ventas, existe un $3 \%$ de informantes que consideran que los precios de autos usados se han incrementado en el 2016, pero la mayoría, es decir, siete de cada diez comerciantes aseguran una disminución de precios, sin embargo, esta reducción no ha influido en el crecimiento de ventas de acuerdo a lo analizado en el párrafo anterior. El $28 \%$ restante afirma que los precios se han mantenido en relación al año 2015.

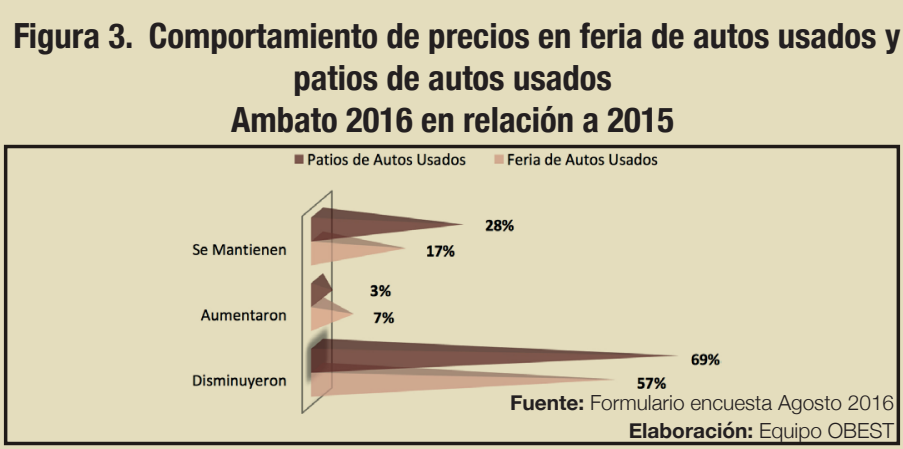

En promedio se comercializan 6 autos usados mensuales en los patios de carros investigados, a pesar de ello, existen casos en donde se comercializa apenas una unidad al mes, así como también, otros locales reportan ventas mensuales de entre 10 y 15 unidades.

En el Boletín de Coyuntura Nro. 9 del OBEST se hizo referencia a la restricción de importaciones y aplicación de salvaguardias, situación que ha afectado al sector comercial automotriz a nivel nacional. Al ser un tema de gran importancia se consulta en esta ocasión a los comerciantes en patios de autos usados que percepción tienen sobre las medidas aplicadas por el Gobierno Nacional, así, el $84 \%$ de informantes afirma haber sido perjudicado con las medidas, el 13\% considera que la situación no les ha beneficiado ni perjudicado y, apenas el $3 \%$ considera que fue beneficiado.

Con el panorama expuesto los comerciantes han formado su perspectiva del negocio para lo que resta del año, un 51\% considera que la situación en relación a ventas empeorará, el 30\% espera y cree que la situación se mantendrá, y apenas el 19\% tiene una perspectiva positiva, considera que las cosas mejorarán hasta diciembre 2016 de acuerdo a lo que han experimentado en estos primeros ocho meses del año.

En cuanto a colores de preferencia por parte de los compradores, el favorito es el blanco, seguido de rojo, plateado y gris. Esta gama de colores coincide con las preferencias de clientes, evidenciada en el sondeo en la feria de autos de Picaihua. Según los comerciantes la preferencia se inclina por colores claros.
Figura 4. Colores preferidos en compra de vehículos usados en patios de carros Ambato 2016

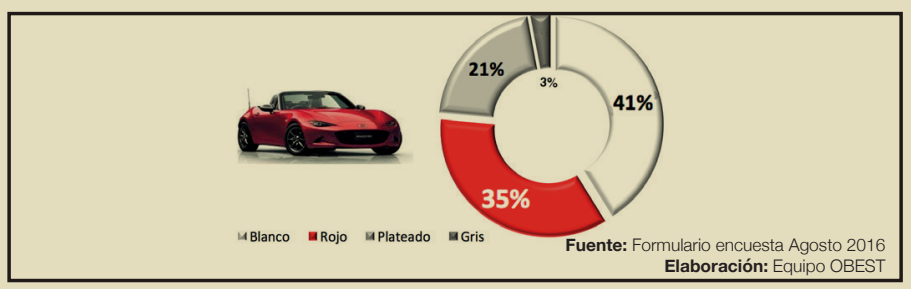

La marca CHEVROLET dentro de los tres análisis realizados ocupa el primer lugar en preferencia de los clientes cuando de elegir un vehículo se trata, en autos nuevos, en autos usados en la feria de Picaihua y en los patios de carros usados, la segunda marca de preferencia en este mercado es TOYOTA, seguida por HYUNDAI, KENWORTH en vehículos pesados y finalmente MAZDA.

Tabla 1. Marcas preferidas en vehículos usados Patios de Carros Ambato 2016

\begin{tabular}{|l|c|}
\hline \multicolumn{1}{|c|}{ MARCA } & PORCENTAJE \\
\hline CHEVROLET & $78 \%$ \\
\hline TOYOTA & $11 \%$ \\
\hline HYUNDAI & $6 \%$ \\
\hline KENWORTH & $3 \%$ \\
\hline MAZDA $\quad$ Fuente: Formulario de encuesta Agosto 2016 \\
Elaboración: Equipo OBEST
\end{tabular}

La complicada situación que atraviesa el sector automotor en comercialización de vehículos, impulsa a los comerciantes a buscar medios para generar mayores ventas, como parte de sus acciones se considera la publicidad. Veinte y nueve locales comerciales de los investigados afirman que realizan anuncios en diferentes medios de comunicación, y ocho de ellos no lo hacen.

\section{Figura 5. Uso de medios publicitarios para ofertar vehículos usados Ambato 2016}

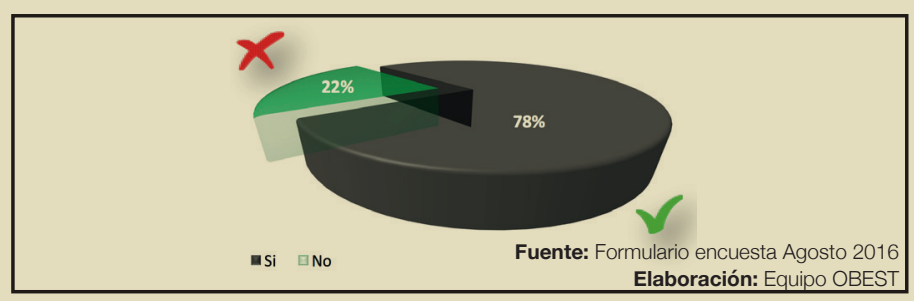

Según los datos registrados, los locales comerciales que realizan publicidad en medios de comunicación muestran una venta promedio de 7 vehículos mensuales, mientras que aquellos que no publicitan sus servicios y productos apenas venden en promedio al mes 2 vehículos. Con esta información se presenta la Figura 6 con el detalle de los principales medios publicitarios utilizados por los patios de carros usados en la ciudad de Ambato:

\section{Figura 6. Medios de publicidad utilizados por patios de vehículos usados Ambato 2016}

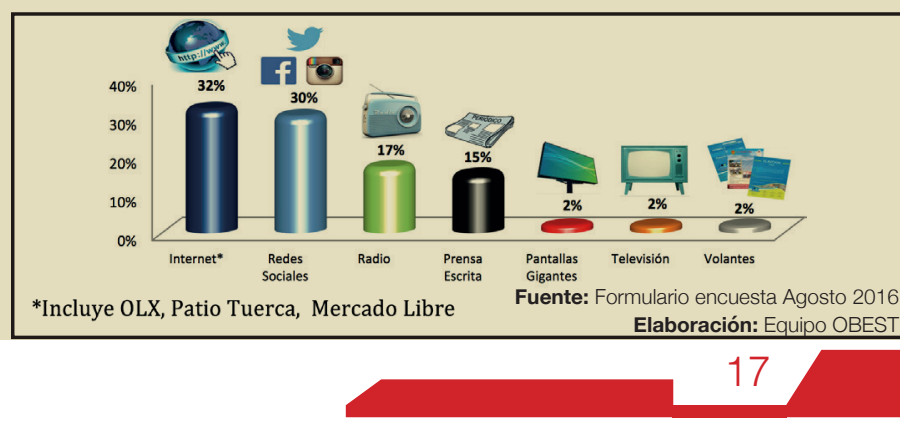


Se evidencia preferencia por los medios publicitarios de menor o ningún costo que en este caso son redes sociales e Internet, donde se incluyen páginas web sobre compra venta libre como OLX, Patio Tuerca y Mercado Libre, la tercera opción de selección es la radio seguida de prensa escrita y en porcentaje minoritario pantallas gigantes, televisión y volantes publicitarios. A pesar de la tendencia decreciente en ventas registrada por los patios de vehículos usados, sólo seis de cada diez negocios realizan algún tipo de promoción para incrementar las ventas.

Entre las formas más comunes de pago al momento de adquirir un vehículo usado, los clientes prefieren en primer lugar los pagos en efectivo con $37,8 \%$, a pesar del peligro que podría representar manejar altas cifras de dinero en efectivo, la segunda forma de pago más utilizada es, el depósito bancario seguido de transferencias bancarias. Este tipo de negocio presenta una nueva opción de pago a diferencia de la feria de autos usados, se entrega crédito directo a ciertos clientes, el 13,5\% de compradores accede a esta opción y sólo el 8,1\% hace su pago por medio de cheque de gerencia.

\section{Figura 7. Modalidades de pago en la compra de autos usados Ambato 2016}

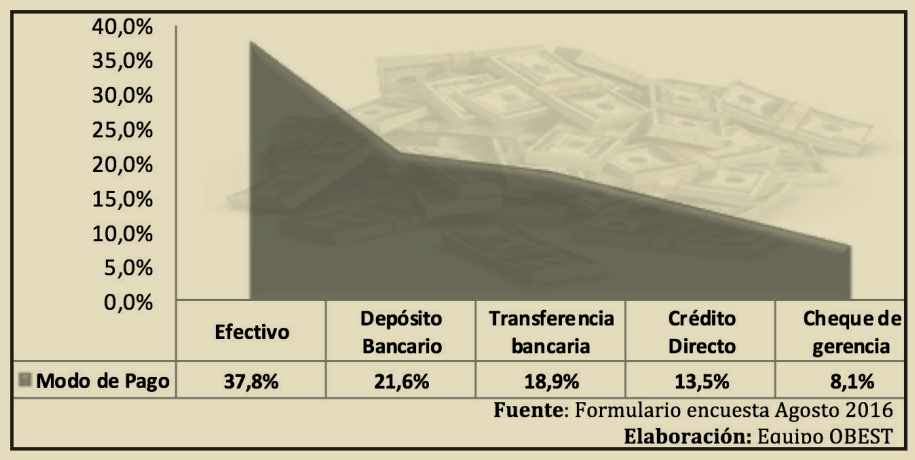

\section{ANEXO}

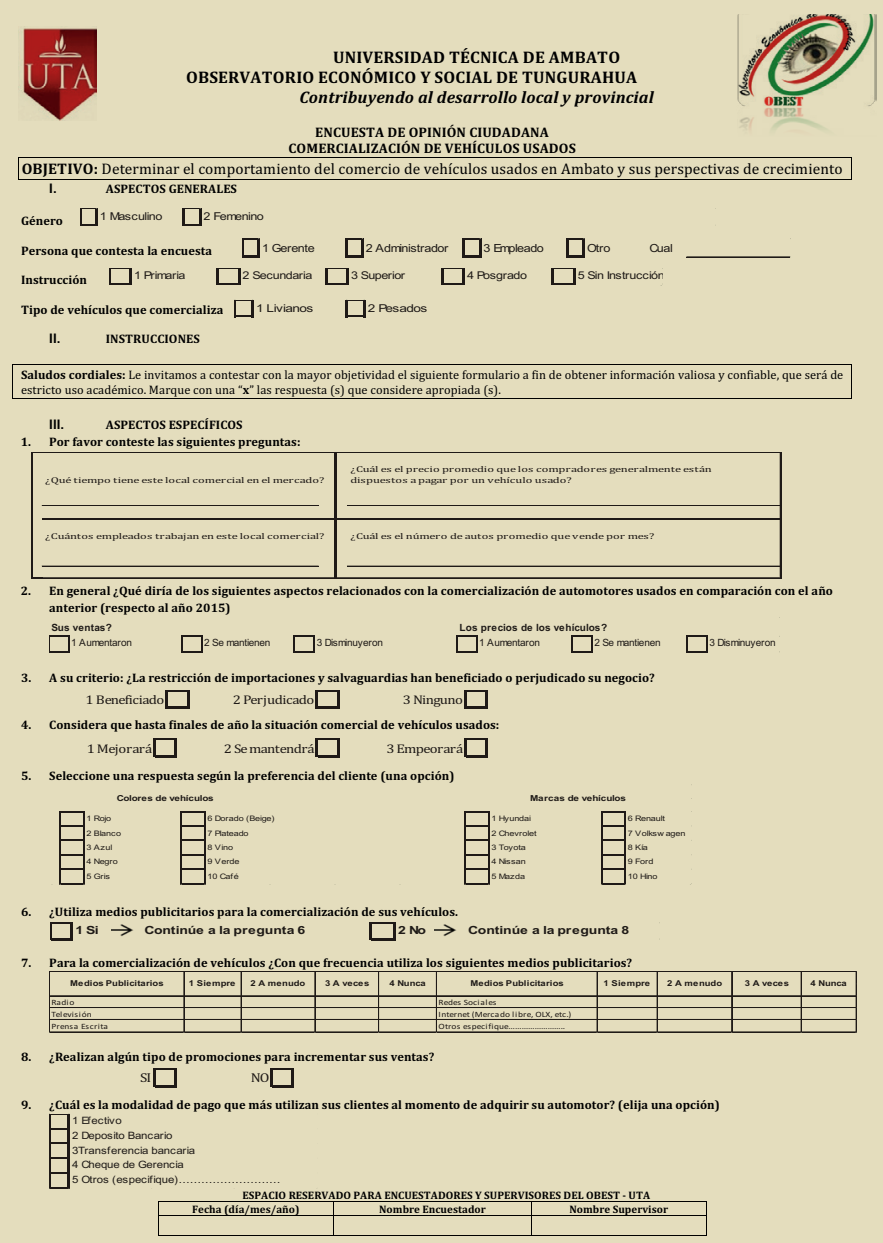

\section{REFERENCIAS}

- Observatorio Económico y Social de Tungurahua - OBEST. (2016). Sondeo de opinión ciudadana a patios de autos usados.

- Observatorio Económico y Social de Tungurahua - OBEST. (2016). Primer Sondeo de

Percepción a Comerciantes de Vehículos Usados - Feria de Autos Cantón Ambato. Disponible en: http://fca.uta.edu.ec/Documentos/ observatorio/BOLETINES\%20PDF/Boletin\%208.pdf

- Observatorio Económico y Social de Tungurahua - OBEST. (2016). Restricción de Importaciones en Tungurahua. Disponible en: http:// fca.uta.edu.ec/Documentos/observatorio/BOLETINES\%20PDF/Boletin9.pdf

\section{Coordinación General}

Econ. Diego Proaño C, Mg.

\section{Diseño, análisis e interpretación}

Econ. Ana María Sánchez T.

\section{Planificación de trabajo de campo}

Econ. Ana María Sánchez T.

Econ. Tatiana Vayas C.

Ing. Fernando Mayorga Núñez

Ing.. Carolina Freire Paredes

\section{Levantamiento de Información}

Equipo técnico OBEST

\section{Colaboración}

Econ. Nelson Lascano 